\title{
Formação humana e seus condicionantes socioeconômicos
}

\author{
Human formation and its socioeconomic conditioning \\ La formación humana y su condicionamento socioeconómico
}

Recebido: 18/11/2021 | Revisado: 25/11/2021 | Aceito: 26/11/2021 | Publicado: 10/12/2021

\author{
Josimar Barbosa dos Santos \\ ORCID: https://orcid.org/0000-0001-5879-5609 \\ Instituto Federal de Alagoas, Brasil \\ E-mail: josimarbarbosaef@gmail.com \\ Edel Alexandre Silva Pontes \\ ORCID: https://orcid.org/0000-0002-9782-8458 \\ Instituto Federal de Alagoas, Brasil \\ E-mail: edel.pontes@ifal.edu.br \\ Eduardo Cardoso Moraes \\ ORCID: https://orcid.org/0000-0002-5117-9421 \\ Instituto Federal de Alagoas, Brasil \\ E-mail: eduardo.moraes@ifal.edu.br
}

\begin{abstract}
Resumo
Este trabalho, a partir de uma revisão bibliográfica, discute o papel do trabalho, da educação e da educação profissional e tecnológica na formação humana. O ser humano tem o trabalho enquanto elemento definidor da sua formação e constituição, de tal modo que todas as relações sociais estão/são a ele condicionadas, inclusive a educação influenciada pelos interesses do mercado, em especial a pública. Os Institutos Federais também sofrem dessas influências, mas tentam resistir e ofertar uma educação integrada, tendo o trabalho como princípio educativo com vistas à formação omnilateral capaz de dar condições aos estudantes ascenderem socialmente e tornarem-se agentes de mudança.
\end{abstract}

Palavras-chave: Formação humana; Educação; Trabalho; Ensino; Educação profissional e tecnológica.

\begin{abstract}
This work, based on a bibliographical review, discusses the role of work, education and professional and technological education in human development. Human beings have work as a defining element of their formation and constitution, in such a way that all social relationships are/are conditioned to it, including education influenced by market interests, especially public ones. Federal Institutes also suffer from these influences, but they try to resist and offer an integrated education, having work as an educational principle with a view to omnilateral training capable of enabling students to ascend socially and become agents of change.
\end{abstract}

Keywords: Human formation; Education; Work; Teaching; Professional and technological education.

\section{Resumen}

Este trabajo, basado en una revisión bibliográfica, analiza el papel del trabajo, la educación y la educación profesional y tecnológica en el desarrollo humano. El ser humano tiene el trabajo como elemento definitorio de su formación y constitución, de tal manera que todas las relaciones sociales están / están condicionadas a él, incluida la educación influida por los intereses del mercado, especialmente los públicos. Los Institutos Federales también sufren estas influencias, pero tratan de resistir y ofrecer una educación integral, teniendo como principio educativo el trabajo con miras a una formación omnilateral capaz de permitir que los estudiantes asciendan socialmente y se conviertan en agentes de cambio.

Palabras clave: Formación humana; Educación; Trabaja; Enseñando; Educación profesional y tecnológica.

\section{Introdução}

O homem nasce em um mundo repleto de elementos naturais e sociais. Esses últimos são historicamente constituídos pela ação humana transformadora do meio natural, doravante trabalho, motivada pela busca da satisfação das mais diversas necessidades para sobrevivência e humanização (Engels, 1999; Saviani, 2011; Della Fonte, 2018), a exemplo da alimentação, abrigo, segurança, locomoção e educação. A contemplação dessas, por mais que ocorra de forma desigual entre as classes sociais, promove a vida em sociedade. A educação formal, nesse processo evolutivo, tem importância crucial ao ter, enquanto 
um de seus papéis, formar os indivíduos para o mercado de trabalho e, principalmente, a formação geral humanística (Saviani, 2011).

A escola, em especial a pública, é determinada em grande medida pelos interesses voltados quase exclusivamente ao atendimento das demandas trabalhistas, haja vista que as bases dessa instituição são definidas por grupos sociais dominantes que também são donos dos meios de produção, assim, tentam ao máximo por aquela em função de seus interesses (Nosella, 2007; Neves \& Pronko, 2008; Frigotto, 2009). Dessa maneira, o currículo escolar, em grande medida, conduz a uma formação fragmentada, incapaz de contemplar os anseios educacionais dos filhos da classe trabalhadora para promover-lhes um maior protagonismo frente à realidade (Araújo, 2019).

A Educação Profissional e Tecnológica (EPT) dos Institutos Federais é voltada à formação para o trabalho e sofre desses mesmos determinantes. Contudo, busca ir além disso e contemplar uma educação ampla dos estudantes, a qual tenha como horizonte a formação de sujeitos críticos e conscientes, capazes de intervir com autonomia nos mais diversos meios em que forem inseridos (Brasil, 2008; Pacheco, 2015). Mas, em meio aos interesses capitalistas, há diversas barreiras para a efetivação plena de um currículo escolar com viés como apresentado anteriormente, uma vez que os donos do modo de produção vigente tendem a mascarar/distorcer os elementos da realidade (fetichismo do capital), como estratégia para encobrir as diversas formas de opressão à classe trabalhadora (Frigotto, 2009).

Ainda, conforme esse autor, a partir dos comandos desse tipo de organização societária, alicerçada sobre a busca pela acumulação de capital, tudo é concebido como mercadoria e sofre suas determinações, inclusive a escola e o próprio ser humano ao vender sua força de trabalho para sobreviver.

Diante desses pressupostos, o presente artigo, a partir de uma revisão bibliográfica, objetiva discutir o papel do trabalho, da educação e da EPT na formação humana.

Assim, pretende-se, a partir de uma discussão com alguns autores como Ciavatta (2014), Della Fonte (2018), Engels (1999), Ferreira (2011), Frigotto (2009), Gramsci (2001), Nosella (2007), Pacheco (2010 e 2015), Pasqualini (2013), Pinto (2011) e Saviani (2011), trazer maior clareza sobre as questões relacionadas à formação humana: como ocorre a formação humana? O trabalho no sistema capitalista e suas facetas: fonte de realização humana ou exploração? Qual o papel da educação, principalmente da EPT para a formação humana em nosso país?

\section{Referencial teórico}

\subsection{A Formação Humana}

O Desenvolvimento Humano advém de duas linhas: a biológica, garantida ao nascer, e a sócio-histórica, adquirida por socialização (Pasqualini, 2013). Não atuamos sobre a primeira, em razão de ser resultado do Desenvolvimento Humano ao longo de milhares de anos, nos quais se sucederam alterações anatômicas significativas, como postura ereta, desenvolvimento das habilidades manuais, dos órgãos da comunicação e do cérebro; encerradas com a chegada ao homo sapiens (Engels, 1999). A partir de então, conforme esse autor, a socialização torna-se determinante principal das mudanças de homens e mulheres, efetivadas por meio da apresentação do mundo natural e cultural enquanto pré-requisito para a humanização.

Assim, a constituição humana não é garantida ao nascer, mas formada pelas experiências sociais, as quais são diretamente dependentes das condições adequadas de vida e educação. Nesse ínterim, a família e depois a escola têm tarefa crucial ao possibilitar o acesso e auxiliar na compreensão do patrimônio cultural pela criança (Pasqualini, 2013).

A evolução histórica do mundo humano é possível pela característica exclusiva dessa espécie: idealização, de forma prévia na mente, das ações a serem executadas pela transformação da natureza em benefício da satisfação dos anseios de homens e mulheres, a partir da ação criadora e criativa denominada trabalho (Saviani, 2011), que acarreta progressos na produção de bens materiais e consequente desenvolvimento e enriquecimento sociocultural. Desta, forma: 
As transformações que a categoria trabalho vem sofrendo ao longo da história da humanidade, diante das diversas mutações vivenciadas pela sociedade nos seus distintos modos de organização e acumulação, provoca reflexos sociais, políticos, ideológicos, econômicos e culturais, haja vista sua condição de categoria determinante da reprodução do ser social (da Silva et al., 2019, p.4).

Para Engels (1999, p.4) o trabalho "é a condição básica e fundamental de toda a vida humana, e isto em tal grau que, em certo ponto, podemos afirmar que o trabalho criou o próprio homem". Homens e mulheres, nas relações de gênero e divisão do trabalho, apresentam variações em diferentes épocas e países, ou melhor, são construídas social e historicamente (Cerqueira, Pontes \& de Melo, 2021).

No que se refere aos conhecimentos necessários aos progressos acima referidos, existem várias instituições formativas, mas a escola é o espaço específico de apreensão dos saberes elaborados e desenvolvidos historicamente e cumpre a importante função de promover a formação humana (Saviani, 2011).

\subsection{Trabalho, classe social e a hegemonia do capital}

Segundo Ferreira (2011), ao contrário do propagado pelo idealismo alemão em que as ideias discutidas eram apartadas da realidade material, o materialismo histórico dialético de Marx, tendo a práxis como objeto fundante da ação humana, entende não haver pensamento alheio à realidade material. Dessa forma, a constituição da consciência se dá pela experiência prática do sujeito na realidade material (Engels, 1999; Frigotto, 2009; Della Fonte, 2018).

$\mathrm{O}$ homem ao agir intencionalmente sobre a natureza e modificá-la, enriquece as suas próprias capacidades, constrói conexões neurais e desenvolve habilidades novas (Engels, 1999; Saviani, 2011; Della Fonte, 2018). O resultado dessa ação, entendida como trabalho em seu sentido ontológico, é a criação de um produto socialmente útil, que expressa os interesses de seu criador (Della Fonte, 2018). Pois, "auxiliado pelos poderes que a sua atividade desperta, o homem ameniza as, originalmente, duras condições impostas pelo meio natural onde vive, e transforma a sua existência de rude, bruta, selvagem, em existência humana" (Ferreira, 2011, p. 154).

Nesse sentido, enquanto condição elementar para sobrevivência humana está a satisfação de necessidades básicas como "comer, beber, se proteger das condições climáticas, garantir a saúde do corpo" (Ferreira, 2011, p. 152). Sem a garantia desses imperativos é impossível ao homem elevar suas possibilidades de uma vida mais digna e ser produtor de sua história com maior protagonismo.

O trabalho enquanto atividade vital humana, como exposto nos últimos dois parágrafos, não pode ser confundido com emprego, pois esse é limitado à troca de determinadas horas de produção por uma remuneração. Esta confusão e, até pode se dizer, sentido dado ao trabalho surge a partir do desenvolvimento das relações sociais produtivas capitalistas, fruto do pensamento hegemônico (Frigotto, 2009). Ainda, conforme esse autor, para entender os diferentes sentidos e significados assumidos pelo trabalho na cultura da classe trabalhadora é necessário analisar a forma como ela se constitui socialmente nos âmbitos da economia, da cultura, da política, da arte e da educação.

Assim, convém destacar o sentido de classe, que na sua origem tinha um sentido relacionado a divisão de acordo com a posse ou não de propriedade pelos romanos, nesses moldes, emergiu das relações econômicas da época; e, no período da revolução industrial, foi definido como conhecemos hoje para designar classes sociais específicas (Williams, 2007, apud, Frigotto, 2009). O autor ainda destaca que não se nasce pertencente à classe trabalhadora ou à classe burguesa, mas é algo socialmente determinado.

Historicamente, temos o embate por poder em variados contextos entre essas duas classes sociais. De um lado, temos a classe burguesa detentora dos meios de produção e da hegemonia (domínio) política e cultural, que não necessariamente precisam trabalhar, pois, vivem da exploração da classe trabalhadora, que, em sua maioria, possuindo somente a força de trabalho, vende-a como meio de garantir sua sobrevivência (Frigotto, 2009). Por outro lado, há disputas contra hegemônicas, 
que buscam por um fim ao domínio em curso, não apenas de ordem da produção material, mas política, cultural e sobretudo da formação que é destinada aos trabalhadores.

Isso põe em evidência uma contradição posta no interior da sociedade cindida em classes sociais, uma vez que os incríveis avanços alcançados na produção de bens e serviços, que promovem a vida social nos causam fascínio e orgulho; por outro lado, causam também indignação pela forma desigual em que se dá o usufruto dessa produção, onde uma significativa parcela da população vive em condições miseráveis (Ferreira, 2011), sem a garantia do mínimo necessário para sobreviver de maneira digna. Enquanto isso há uma minoria com diversos privilégios que ostenta um enorme patrimônio financeiro e material.

Na sociedade capitalista, os verdadeiros responsáveis por toda construção material humana têm acesso a uma mísera parcela do resultado de seu trabalho. Nesse sentido, o trabalhador ao não ter a possibilidade de usufruto do bem por ele produzido, não cria relação desse com sua vida. Dessa maneira, tem-se um estranhamento, onde o produtor não se reconhece no objeto por ele feito, já que é propriedade de outra pessoa e há uma neutralidade do trabalhador com relação à determinação do que e como produzir (Ferreira, 2011). O trabalho, nesse ínterim, resume-se à venda da força produtiva por um salário, não tendo um fim em si mesmo para a satisfação de uma carência (trabalho natural), mas enquanto meio de garantir a subsistência do trabalhador (trabalho social).

De acordo com Frigotto (2009, p. 182) "Uma das mudanças profundas para a classe trabalhadora situa-se no fato de que cada vez mais a ciência e a tecnologia se tornam forças produtivas do capital e se voltam contra a classe trabalhadora". A máquina, por exemplo, representa um avanço científico que deveria elevar as condições de trabalho, mas torna-se mais um instrumento nas mãos dos capitalistas para aumentar os seus lucros e ampliar a servidão humana no interior das fábricas. Nessa perspectiva, o valor de homens e mulheres assalariados é comparável ao de máquinas; em que são limitados por controles de tempo e dinheiro em favor da produtividade.

Temporalmente, o homem, em especial das classes menos favorecidas economicamente, esteve mais voltado ao trabalho relacionado ao mundo da necessidade: o que faz para sobreviver; e torna-se cada vez mais difícil, em virtude da escassez de tempo e recurso, a realização de atividades humanas como livre criação (mundo da liberdade): aquilo que verdadeiramente nos promovem como ser humano, a exemplo, da cultura, lazer, ações sociais e pesquisa (Ferreira, 2011).

A superação do capitalismo deve se dá na luta de uma coletividade consciente de que essa ruptura é necessária, no plano da práxis, na busca pela utopia do socialismo e da educação omnilateral, unitária e politécnica no terreno contraditório atual (Frigotto, 2009).

Ao homem, sobretudo da classe trabalhadora, só é possível a libertação da condição do reino da necessidade para o reino da liberdade de forma plena, a partir da organização social comunista, a qual pressupõe a superação da propriedade privada (Ferreira, 2011). Esse autor também menciona que, nessas condições existiria a possibilidade do usufruto mais qualitativo das riquezas naturais e sociais, onde o homem livremente escolheria a atividade que gostaria de desenvolver como pescar, caçar, pintar, plantar, sem, contudo, tornar nenhuma delas seu ofício.

Nessa forma de organização social, seria possível um projeto educacional voltado à formação omnilateral, em seu sentido holístico. Mas, é possível, ainda na sociedade capitalista, um currículo escolar com tal viés? No próximo tópico discutiremos com alguns autores a respeito das barreiras e perspectivas sobre essa questão tão salutar, sobretudo para os filhos da classe trabalhadora, que tem na educação a oportunidade de galgar melhores condições de vida.

\section{Metodologia}

Trata-se de um artigo de pesquisa qualitativa que utiliza o método de revisão bibliográfica com um conjunto ordenado de procedimentos de busca por reflexões sobre o tema, atento ao objeto de estudo, o qual busca resumir, analisar e discutir 
informações já disponíveis em artigos, livros, dissertações e revistas (Brasileiro, 2013). Neste estudo, realizou-se uma pesquisa bibliográfica com o intuito de reunir produções de teóricos que são referências quando discutimos sobre o papel do trabalho, da educação e da EPT na formação humana em uma perspectiva integrada. Assim, foram selecionadas obras como Ciavatta (2014), Della Fonte (2018), Engels (1999), Ferreira (2011), Frigotto (2009), Gramsci (2001), Nosella (2007), Pacheco (2010 e 2015), Pasqualini (2013), Pinto (2011) e Saviani (2011) para compor o presente estudo e trazer maior clareza sobre as questões relacionadas à formação humana: como ocorre a formação humana? O trabalho no sistema capitalista e suas facetas: fonte de realização humana ou exploração? Qual o papel da educação, principalmente da EPT para a formação humana em nosso país?

Desta forma, no que diz respeito à forma de abordagem, configura-se como uma produção científica de cunho qualitativo, pois não se privilegia a mera quantificação dos dados, e sim, a análise aprofundada dos elementos contidos na realidade estudada (Severino, 2017).

\section{Resultados e Discussão}

\subsection{O papel da educação}

Desde os primórdios, o trabalho assume papel central para a existência e o desenvolvimento humano. De início, era marcado pelo aprendizado por meio da repetição dos gestos, dessa forma, tinha-se o trabalho como princípio educativo, ou seja, a formação para o trabalho ocorria na prática de seu cotidiano com os seus semelhantes: aprendia-se fazendo.

Mas, com a complexificação do modo produtivo e das necessidades formativas humanas, fruto de seu processo de desenvolvimento social, tem-se a criação da escola enquanto espaço mais propício à apreensão dos saberes, especialmente dos elaborados e desenvolvidos historicamente (Saviani, 2011). Em sua gênese, o acesso era privilégio das classes mais influentes e favorecidas economicamente, mas, com a demanda do próprio mercado de trabalho e das relações sociais, cada vez mais complexas, surge a necessidade de democratizá-la (Pinto, 2011).

Nesse sentido, diversos ordenamentos legais foram instituídos com o objetivo de organizar e conferir maior importância à educação e à escola no cenário brasileiro, dentre os quais a Constituição Federal de 1988 ocupa função salutar. No artigo 205 dessa lei está disposto que:

a educação, direito de todos e dever do Estado e da família, será promovida e incentivada com a colaboração da sociedade, visando ao pleno desenvolvimento da pessoa, seu preparo para o exercício da cidadania e sua qualificação para o trabalho. (Brasil, 1988).

O papel da educação escolar é crucial à humanização e aos diversos avanços na produção da existência social, para Saviani (2011, p. 13):

diz respeito, de um lado, à identificação dos elementos culturais que precisam ser assimilados pelos indivíduos da espécie humana para que eles se tornem humanos e, de outro lado e concomitantemente, à descoberta das formas mais adequadas para atingir esse objetivo.

Assim, essas características de selecionar os conteúdos mais relevantes que devem ser trabalhados, bem como a sua sistematização lógica, os melhores meios e procedimentos para promover o processo de ensino-aprendizagem com cada um deles consistem na diferenciação formativa de outros espaços como o familiar, religioso e variados lugares de sociabilidade. A organização e os métodos que regem o conjunto de atividades nucleares da escola, situadas no espaço e tempo pedagógico e suas mediações necessárias, são previstos no currículo escolar, o qual é elaborado conforme determinações sociais e políticas, e toma direcionamentos conservadores ou humanísticos segundo o grupo no poder (Saviani, 2011).

Nesse sentido, o direcionamento que é dado aos saberes escolares e sua concepção ético-política muda conforme os 
imperativos econômicos e político-sociais das metamorfoses no processo produtivo no capitalismo na sua fase neoliberal (Neves \& Pronko, 2008). Isso implica na necessidade de formar trabalhadores cada vez mais flexíveis e empregáveis, capazes de lidar com o cenário atual repleto de novas tecnologias e excesso de informações (Moraes, 2020). Esse processo exige "alterações periódicas no conteúdo e na forma de preparação para o trabalho nessas mesmas determinações no interior da nossa formação social" (Neves \& Pronko, 2008, p. 23).

Desta forma, as instituições de ensino são moldadas, em grande medida, segundo esses imperativos do capital e direcionam a uma formação mercadológica, conforme os ideais da individualidade, competitividade e empregabilidade, como valores preponderantes desse sistema em contraposição a uma formação geral humanística.

Para compreender as condições desiguais de vida e educação na constituição das relações sócio-históricas de formação da população brasileira é preciso, de forma contextualizada, situá-las em meio às profundas desigualdades socioculturais e econômicas, em especial, dos processos educativos formais e sua subordinação aos interesses capitalistas e todas as suas formas de alienação (Frigotto, 2009). Ainda nessa ótica, "compreender o que é o ser humano implica indagar como ele se faz, como vive, o que produz, como produz e, portanto, que tipo de formação propicia o trabalho em dado momento" (Della Fonte, 2018).

Historicamente, a educação esteve correlacionada ao trabalho (Nosella, 2007), visto que as ações humanas para sobrevivência e todas as relações sociais sempre demandaram a aquisição de conhecimentos por diferentes vias, seja por meio da informalidade no cotidiano ou a partir de instituições formais destinadas a estes propósitos formativos.

O projeto educacional brasileiro ao longo do tempo foi determinado, em grande medida, por questões de ordem política e econômica, correlacionadas à dualidade entre o trabalho manual e o trabalho intelectual, conforme as metamorfoses da organização social (Neves \& Pronko, 2008; Frigotto, 2009). Vale salientar que a classe dominante, possuidora dos meios de produção de bens, comanda os meios de produção do conhecimento (Nosella, 2007; Neves \& Pronko, 2008; Frigotto, 2009). Nesse sentido, "a educação no Brasil foi historicamente pensada para atender a uma elite dirigente" (Pinto, 2011, p. 55).

Mas, de acordo com Frigotto (2009), há possibilidade, diante das contradições reais presentes no capitalismo e forças em conflito, de os educadores disputarem as novas bases de conhecimento demandadas pelo processo produtivo, a partir dos fundamentos da escola unitária e da educação omnilateral.

Nesse sentido, a escola pode transpor as determinações imediatas da produção capitalista, nas contradições postas em seu interior, pois:

A escola pode ser útil à classe trabalhadora como instrumento de barganha por melhores condições de trabalho, como instrumento de alargamento do grau de conscientização política e como instrumento da formulação de uma concepção de mundo emancipatória das relações sociais vigentes. Mas, para que a educação escolar se transforme efetivamente em instrumento de conscientização da classe, ela precisa superar a sua sempre crescente subsunção aos imperativos técnicos e ético-políticos da mercantilização da vida, privilegiando na sua estruturação curricular a omnilateralidade e a politecnia. (Neves \& Pronko, 2008, p. 29).

Conforme essas autoras, a escola é objeto de reprodução dos interesses da classe hegemônica, mas serve aos interesses da classe trabalhadora quando os processos formativos são constituídos pelos princípios da omnilateralidade ou politecnia, que possibilitem ao estudante formar uma visão de totalidade dos fenômenos sociais estudados em articulação com seus conhecimentos prévios, a qual será "alcançada quando este for capaz de elaborar uma síntese em seu pensamento (contribuição das diferentes ciências) articuladamente, permitindo a constatação, interpretação, compreensão e explicação da realidade" (Santos, Silva \& Prates, 2017).

Nesse sentido, as lições deixadas pela pedagogia socialista, conforme Ciavatta (2014) corroboram a elucidação dessas discussões sobre os diferentes papéis da escola e sua relação com o trabalho. A primeira lição ao mencionar que, no modo de 
produção vigente, a inter-relação entre trabalho e escola sempre será alvo de disputa. A segunda lição ao indicar que o papel da pedagogia socialista a partir da produção de seu conhecimento, não se destina aos interesses do mercado, mas ao registro e à construção da história da educação para a humanização. A terceira lição ao informar que as disputas para romper com essa subordinação da escola perante os imperativos do trabalho devem ser trilhadas em conjunto com as lutas sociais em prol das melhorias de vida social.

\subsection{A EPT: da formação assistencialista à integrada e a dualidade educacional}

A Lei de Diretrizes e Bases da Educação Nacional n. 9.394, de 20 de dezembro de 1996 (LDBEN), em seu artigo 39, estabelece que "a educação profíssional e tecnológica, no cumprimento dos objetivos da educação nacional, integra-se aos diferentes níveis e modalidades de educação e às dimensões do trabalho, da ciência e da tecnologia" (Brasil, 1996). Nesse mesmo artigo, em seu parágrafo segundo, essa lei estipula a abrangência da EPT na formação inicial e continuada ou qualificação profissional; na educação profissional técnica de nível médio; e na educação profissional tecnológica de graduação e pós-graduação. Desta maneira, tem-se uma verticalização do ensino, em que os professores podem lecionar em qualquer um desses níveis de ensino ofertados (Pacheco, 2010).

Torna-se relevante apresentar alguns marcos importantes da história da EPT e, consequentemente da Rede Federal de Educação Profissional, Científica e Tecnológica (RFEPCT) da qual faz parte, em sua trajetória de mais de 110 anos de existência.

A RFEPCT teve sua origem por meio da criação de uma rede de Escolas de Aprendizes-Artífices em 1909, cuja função era meramente assistencialista e moralizadora dos jovens das classes pobres e ao longo do tempo sofreu diversas metamorfoses, evoluindo tanto em relação a essa finalidade inicial quanto em expansão territorial e de alcance de suas ações educativas (Neves \& Pronko, 2008).

Com a Reforma Gustavo Capanema, em 1942, o ensino profissional é sistematizado e integrado ao sistema educacional brasileiro, estimulado pelas transformações urbanas e industriais, advindas do avanço da industrialização (Pinto, 2011). Ainda, conforme esse autor, a dualidade esteve presente nas políticas de educação profissional e tecnológica, com uma formação humanística direcionada pelo viés do trabalho como princípio educativo e outra limitada à preparação prática para o mercado.

No período da ditadura militar, com a criação das Escolas Técnicas Federais, o objetivo central era a formação para o mercado (Neves \& Pronko, 2008). Nesse período, conforme essas autoras, ocorreu uma acentuada valorização da educação profissional, num contexto de crescimento econômico e transformações sociais. Na década de 1970, a reestruturação produtiva com a crescente mudança do sistema taylorista-fordista para o sistema toyotista, caracterizado por uma maior flexibilização produtiva, implicou em novas demandas de formação. A partir de então, valoriza-se uma formação com base em competências diversas, com vistas a formar trabalhadores aptos a desempenhar diversas tarefas profissionais, para além de especialistas (Pinto, 2011).

No início do século XXI, com a eleição do presidente Lula, foi dada maior atenção às políticas públicas e não somente ao mundo produtivo (Pinto, 2011; Pacheco, 2015). Nesse contexto, ainda segundo esses autores, a instituição do Decreto $\mathrm{n}$. 5154/2004 marcou um avanço ao possibilitar a integração do ensino profissional ao ensino médio, na perspectiva de uma formação humanística que contemple a docência das ciências e humanidades no processo de formação dos trabalhadores.

A criação dos Institutos Federais (IFs) e sua integração à RFEPCT ocorre por meio da Lei n. 11.892, de 29 de dezembro de 2008. Pelo disposto nessa lei, a educação preconizada por esse tipo de escola não se restringe à formação de trabalhadores para o mercado, uma vez que fica estabelecido o compromisso com uma prática educativa que trabalhe de forma inseparável o ensino, a pesquisa e a extensão e busque uma formação ampla (Brasil, 2008), segundo a perspectiva de uma 
educação integrada, politécnica e omnilateral dos estudantes. Nessa ótica, "os Institutos Federais como política pública representa trabalhar na superação da representação existente: a de subordinação quase absoluta ao poder econômico" (Pacheco, 2010, p. 17).

A formação integrada, pretendida pelas ações educativas no âmbito dos IFs, tem sua origem na educação socialista que almejava ser omnilateral com vistas ao desenvolvimento humano nos seus amplos aspectos corporais, psicológicos, culturais, políticos e científico-tecnológicos (Ciavatta, 2014). Essa autora também menciona que na realidade brasileira das amplas desigualdades entre as classes, essa integração surge como uma imposição da realidade da população trabalhadora, em que o trabalho é incorporado à educação básica enquanto princípio educativo em associação com a ciência e a cultura.

O significado de ensino integrado não se limitada a inter-relação entre educação geral e profissional, mas a busca por consolidá-lo com os ideais de uma formação politécnica, omnilateral e de uma escola unitária; bem como pretende pôr um fim às desigualdades sociais e educacionais brasileiras, à cisão de classes sociais, à separação entre formação para o trabalho manual ou para o trabalho intelectual, e defender a democracia e a escola pública (Ciavatta, 2014).

Importante mencionar que, no decorrer do tempo, houve diversos embates sobre as interpretações dadas ao termo politecnia, mas preservou-se o sentido relacionado à educação omnilateral voltada a uma "formação em todos os aspectos da vida humana - física, intelectual, estética, moral e para o trabalho, integrando a formação geral e a educação profissional" (Ciavatta, 2014, p. 190-191).

O ensino na EPT, nessa perspectiva, associa a formação geral à formação profissional em todos os níveis de ensino, com práticas pedagógicas que priorizam o trabalho como princípio educativo tendo como finalidade a superação da divisão entre trabalho manual e trabalho intelectual. Pois, todo profissional é um intelectual e precisa de uma formação dos conhecimentos das ciências e da concepção humanística histórica, para além dos saberes técnicos necessários ao ofício, capaz de capacitá-lo para planejar sua prática e também desenvolvê-la autonomamente e, dessa forma, poder comandar altos cargos como dirigente (Gramsci, 2001). Ainda com relação a essa dicotomia no âmbito da formação para o trabalho, conforme Pacheco (2015, p. 29, grifo do autor),

trata-se de superar a divisão do ser humano entre o que pensa e aquele que trabalha, produzida pela divisão social do trabalho, presente na formação voltada ao "treinamento" para a execução de determinadas tarefas. Antes de formar o profissional, trata-se de formar o cidadão, capaz de compreender o processo produtivo e seu papel dentro dele, incluindo as relações sociais estabelecidas a partir daí. Essas relações ocorrem dentro de um determinado processo histórico onde o trabalho em busca da satisfação das necessidades materiais e subjetivas possibilita ao ser humano construir novos conhecimentos.

A educação profissional aparentemente democrática, na verdade, destina-se à conformação das desigualdades entre classes, pois cada grupo social tem uma escola com um direcionamento específico tradicional, dirigente ou instrumental (Gramsci, 2001). Nesse sentido, os Institutos Federais representam um avanço importante, mas não encerra as terríveis desigualdades educativas presentes na realidade educacional brasileira, principalmente pelo fato de seu reduzido número de estudantes atendidos quando comparado ao das escolas da rede estadual, que “[...] respondem por cerca de $80 \%$ das matrículas do Ensino Médio Brasileiro [...]” (Araújo, 2019, p. 73).

Assim, tem-se, de acordo com esse autor supracitado, uma dualidade nessa etapa da educação básica e que foi ampliada com a reforma do ensino médio, por acarretar em uma precarização ainda maior das escolas públicas estaduais destinadas a uma formação cada vez mais instrumental dos jovens da classe trabalhadora para atuarem em trabalhos simples, dificultando a possibilidade de ascensão social desses. Por outro lado, os IFs e as escolas particulares têm relativa autonomia e podem resistir a reformas dessa natureza. Gramsci salienta:

se se quer destruir esta trama, portanto, deve-se não multiplicar e hierarquizar os tipos de escola profissional, mas criar um tipo único de escola preparatória (primária-média) que conduza o jovem até os umbrais da escolha 
profissional, formando-o, durante este meio tempo, como pessoa capaz de pensar, de estudar, de dirigir ou de controlar quem dirige. (2001, p. 49).

Com efeito, isso seria possível em uma sociedade com condições socioeconômicas que, diferente da realidade brasileira, permitissem ao jovem terminar a educação básica e só então escolher uma profissão. A educação integrada, diante da situação posta, e "tendo como fundamento a integração entre trabalho, ciência e cultura, esse tipo de ensino acirra contradições e potencializa mudanças" (Ciavatta, 2014, p. 199). Haja vista que,

O que se propõe é uma formação contextualizada, banhada de conhecimentos, de princípios e de valores que potencializam a ação humana na busca de caminhos de vida mais dignos. Assim, derrubar as barreiras entre o ensino técnico e o científico, articulando trabalho, ciência e cultura na perspectiva da emancipação humana, é um dos objetivos basilares dos Institutos Federais. Sua orientação pedagógica deve recusar o conhecimento exclusivamente enciclopédico, assentando-se no pensamento analítico, buscando uma formação profissional mais abrangente e flexível, com menos ênfase na formação para ofícios e mais na compreensão do mundo do trabalho e em uma participação qualitativamente superior nele. Um profissionalizar-se mais amplo, que abra infinitas possibilidades de reinventar-se no mundo e para o mundo, princípios esses válidos, inclusive, para as engenharias e as licenciaturas. (Pacheco, 2015, p. 14).

$\mathrm{Na}$ EPT o foco é a formação humana, e na consecução dessa tarefa o trabalho, enquanto princípio educativo, tem função central. A educação para o trabalho, dessa maneira, busca promover o conhecimento a partir das experiências concretas do homem com vistas à sua emancipação, habilitando-o como agente transformador de seu meio, bem como a uma sociedade mais democrática, inclusiva e equilibrada social e ambientalmente (Pacheco, 2015).

\section{Considerações Finais}

Esse trabalho visou elucidar as questões relacionadas à formação humana: como ocorre a formação humana? $\mathrm{O}$ trabalho no sistema capitalista e suas facetas: fonte de realização humana ou exploração? Qual o papel da educação, principalmente da EPT para a formação humana no Brasil?

Com efeito, o ser humano tem o trabalho enquanto elemento definidor da sua formação e constituição, de tal modo que todas as relações sociais estão/são a ele condicionadas no decorrer do tempo.

Na sociedade brasileira regida pelo modo de produção capitalista na sua fase neoliberal, o trabalho é controlado segundo os princípios da acumulação de capital. De maneira que a industrialização e sua produção mecanizada, o crescente desemprego, bem como a uberização do trabalho impõem aos trabalhadores condições trabalhistas severas e influenciam a forma como a educação, em especial a pública, é organizada.

Em sua gênese, a escola era privilégio da classe dominante, mas os avanços sociais e produtivos demandaram a sua democratização para a classe trabalhadora. Isso não ocorreu de maneira despretensiosa, mas com o objetivo de formar operários para atender as demandas capitalistas, por isso a última etapa da educação básica ganha maior atenção. Assim, a escola pública de ensino médio, principalmente as estaduais, sempre foram marcadas pela precarização do ensino ofertado e, com a reforma do ensino médio, a pretensão dessa formação fragmentada para a classe trabalhadora ocupar cargos simples foi evidenciada mais incisivamente.

A EPT ofertada nos IFs, por mais que sofra também com os diversos ataques empreendidos contra a educação, sobretudo após o golpe parlamentar de 2016, têm uma maior autonomia e tentam resistir, mantendo sua essência pela oferta educacional voltada a uma formação humana integral que tenha o trabalho como princípio educativo e busque formar cidadãos autônomos, com vistas à transformação de suas vidas e das realidades onde forem inseridos.

Cumpre salientar que a posição de destaque e referência ocupada pelos Institutos Federais decorre de conquistas históricas. Nesse sentido, a defesa pela manutenção dessa qualidade e repúdio às contrarreformas deve ser uma constante em 
nossa luta em favor da qualidade da educação da classe trabalhadora e a busca pela redução das desigualdades na sua oferta.

\section{Referências}

Araújo, R. M. D. L. (2019). Ensino médio brasileiro: dualidade, diferenciação escolar e reprodução das desigualdades sociais. Uberlândia: Navegando Publicações.

Brasil (1996). LEI No 9.394, DE 20 DE DEZEMBRO DE 1996. Estabelece as diretrizes e bases da educação nacional.

Brasil (2008). LEI No 11.892, DE 29 DE DEZEMBRO DE 2008. Institui a Rede Federal de Educação Profissional, Científica e Tecnológica, cria os Institutos Federais de Educação, Ciência e Tecnologia, e dá outras providências, Brasília: DF.

Brasileiro, A. M. M. (2013). Manual de produção de textos acadêmicos e científicos. São Paulo: Atlas.

Cerqueira, P. C., Pontes, E. A. S., \& de Melo, B. M. (2021). A mulher no mundo do trabalho: a escolha do curso "masculino" e a inserção no estágio. Research, Society and Development, 10(13), e209101321046-e209101321046.

Ciavatta, M. (2014). O ensino integrado, a politecnia e a educação omnilateral. Por que lutamos? Trabalho \& Educação, 23(1), 187-205.

da Silva, A. C., Henrique, A. L. S., \& de Oliveira Neta, O. M. (2019). A inter-relação entre trabalho, educação e formação humana: implicações na docência em Educação Profissional. Research, Society and Development, 8(1), e3381594.

Della Fonte, S. S. (2018). Formação no e para o trabalho. Revista Educação Profissional e Tecnológica em Revista, Rede Federal de Educação Profissional e Tecnológica, 2(2).

Englels, F. (1999). O Papel do Trabalho na Transformação do Macaco em Homem. Ed. Eletrônica: Ridendo Castigat Mores, 1999.

Ferreira, A. L. S. (2011). Trabalho, Estranhamento e Comunismo em Marx. $6^{\circ}$ Encontro de Pesquisa na Graduação em Filosofia da Unesp. 4(1).

Frigotto, G. (2009). A polissemia da categoria trabalho e a batalha das ideias nas sociedades de classe. Revista Brasileira de Educação, 14(40).

Gramsci, A. Caderno 12 (1932) - Apontamentos e notas dispersas para um grupo de ensaios sobre a história dos intelectuais. In: Gramsci, A. Cadernos do Cárcere - Volume 2. Os intelectuais. O princípio educativo. Jornalismo. Tradução de Carlos Nelson Coutinho. (2a ed.), Civilização Brasileira: 13-53.

Moraes, E. C. (2020) Reflexões acerca das Soft Skills e suas interfaces com a BNCC no contexto do Ensino Remoto. Research, Society and Development, 9(10), e9499109412.

Neves, L. M. W., \& Pronko, M. A. (2008). O mercado do conhecimento e o conhecimento para o mercado: formação para o trabalho complexo no Brasil contemporâneo. Rio de Janeiro: EPSJV.

Nosella, P. (2007). Trabalho e perspectiva de formação dos trabalhadores: para além da formação politécnica. Revista Brasileira de Educação, 12(34).

Pacheco, E. M. (2010). Os Institutos Federais: Uma Revolução na Educação Profissional e Tecnológica. Ministério da Educação e Cultura. Natal: IFRN, 2010.

Pacheco, E. M. (2015). Fundamentos político-pedagógicos dos institutos federais: diretrizes para uma educação profissional e tecnológica transformadora. IFRN.

Pasqualini, J. C. (2013). Periodização do desenvolvimento psíquico à luz da escola de Vygotsky: a teoria histórico-cultural do desenvolvimento infantil e suas implicações pedagógicas. In: Marsiglia, A.C.G. (Org.). Infância e pedagogia histórico-crítica. Autores Associados.

Pinto, A. H. (2011). Trabalho, ciência e cultura como princípio e fundamento da educação profissional. In: Cosme, G. M. Et al. Repensando o PROEJA: concepções para a formação de educadores. Vitória-ES, IFES, p. 49-66.

Santos, J. B., Silva, J. L., \& Prates, A. C. (2017) Educação física escolar e desenvolvimento Humano. In: XX CONBRACE, VII CONICE, 2017, Goiânia, GO. Anais [...], Goiânia, GO, 1410-1412. http://congressos.cbce.org.br/index.php/conbrace2017/7conice/

Saviani, D. (2011) Pedagogia histórico-crítica: primeiras aproximações. (11a ed.), Autores Associados.

Severino, A. J. (2017). Metodologia do trabalho científico [livro eletrônico]. (2. ed.) São Paulo: Cortez, 4,4. 